\title{
Evaluation of Role of Captopril and Erdosteine in Protection of The Lung against Bleomycin-Induced Injury in Rats
}

Esam Omar Kamel ${ }^{1 *}$, Alsayed Abdel Rahman Abdel Hady², Al-Sayed Al-Hady Abd-EIrahman ${ }^{3}$, Mahmoud Mohamed Diab ${ }^{4}$

1-Department of Medical Histology and Cell Biology, Faculty of Medicine, Al-Azhar University, Assuit Branch, 2- Department of Human Anatomy and Embryology, Faculty of Medicine, Helwan University, 3- Department of Human Anatomy and Embryology, Faculty of Medicine, Port Said University, 4-Department of Human Anatomy and Embryology, Faculty of Medicine, Al-Azhar University, Cairo

*Corresponding author: Esam Omar Kamel, Tel: +201143189339, EMail: dr_esamomar@yahoo.com

\begin{abstract}
Background: bleomycin (BLM) is a chemotherapeutic agent having a wide use in the clinical field. Its most serious side effect is the life-threatening pulmonary toxicity. Objective: this study aimed to evaluate the role of captopril and erdosteine (ERD) in lung protection against BLM-induced injury in rats. Material and Methods: thirty-two rats were categorized into 4 equal groups. Group I: rats received distilled water. Group II: rats injected intaperitonealy with $0.5 \mathrm{mg}$ of BLM sulphate dissolved in $0.5 \mathrm{ml}$ saline twice weekly for 4 weeks. Group III: rats received BLM in a dose as in group II \&ERD by a dose of $10 \mathrm{mg} / \mathrm{kg} /$ day orally, 2 days before BLM administration. Group IV: rats received BLM in a dose as in group II and captopril with a dose of $5 \mathrm{mgkg}$ orally for 4 weeks, 2 days before BLM administration. Results: rats treated with BLM revealed disturbance of lung structure. There were marked cellular infiltration and thickening in alveolar septa with wide variation in the diameter of alveoli. Blood vessels were congested. Extravasation of blood into interalveolar septa was observed. Large number of vacuolated cuboidal cells was noticed. Large amounts of collagen fibers around the bronchioles and few collagen fibers in the interalveolar septa were detected. Sections of rats treated with BLM and ERD showed apparently normal lung structure but, some collapsed alveoli with thick septa were still noticed. Sections treated with BLM and captopril showed lesser structural improvement than ERD-treated sections. Conclusion: administration of captopril and ERD partially improved BLM-induced pulmonary fibrosis in rats.
\end{abstract}

Keywords: lung, alveoli, fibrosis, bleomycin, captopril, erdosteine.

\section{INTRODUCTION}

Idiopathic pulmonary fibrosis (IPF) is a chronic and disabling interstitial lung disease poorly responding to medical treatment and it has a high mortality rate because it usually causes respiratory failure ${ }^{(\mathbf{1})}$.It has been claimed that inflammatory cells which accumulate in the lower respiratory passages resulting from repeated respiratory tract infections release considerable amounts of reactive oxygen species (ROS) leading to depletion in glutathione, the major factor of the lung antioxidant defense system leading to lung injury and fibrosis ${ }^{(2)}$. Bleomycin (BLM) is an antitumor agent isolated from a strain of Streptomyces verticillus. It has been widely used to treat a variety of tumors including squamous cell carcinoma of the head, cervix and esophagus, as well as, Hodgkin's and non-Hodgkin's lymphomas ${ }^{(\mathbf{3})}$. BLM is selectively affecting the lungs because they lack the enzymes that hydrolyze the L-aminoalanine moiety of BLM, which prevent its metabolite from binding metals such as iron ${ }^{(4)}$.Using superoxide dismutase, glutathione, dimethylurea and metalloporphyrin aimed toreduce oxidative stress and to decrease BLM -induced lung injury and fibrosis ${ }^{(5)}$.Skin and lungs were found to be highly sensitive to BLM-induced injuries.This was explained by low concentration of BLM hydrolase enzyme. But, still there are some tissues can resist BLM-induced problems which can be correlated with the presence of a BLM hydrolase enzyme in these tissues ${ }^{(\mathbf{6})}$.

Angiotensin-converting enzyme

(ACE) inhibitors are known to be effective in treatment of many diseases including coronary artery diseases, hypertension, diabetic nephropathy and congestive heart failure. The therapeutic effect of these drugs is mostly by modulation of the renin-angiotensin system $^{(7)}$.It was found that ACE inhibitors, mainlycaptopril are effective in improvement of induced lung fibrosis in animal models ${ }^{(\mathbf{8})}$.Erdosteine (ERD) is an antioxidant known to have a mucolytic effect, specifically it is a thiol derivative developed for the treatment of chronic obstructive bronchitis, including acute infective exacerbation of chronic bronchitis ${ }^{(9)}$.

Objective:

This study aimed to evaluate the role of captopril and erdosteine in lung protection against BLM-induced injury in rats.

\section{MATERIAL AND METHODS}

Animals, drugs used and dosage:

The present study was carried out on 32 adult male albino rats weighing 130-150 gm. They were obtained from the animal house of the Faculty of Medicine, Al-Azhar University, Cairo, Egypt. The 
animals were kept under suitable conditions for 1 week to adapt and maintained in stainless steel cages at normal temperature $\left(22^{\circ} \mathrm{C} \pm 5^{\circ} \mathrm{C}\right)$ under a $12: 12$ hour light - dark cycle. They were fed laboratory diet (Bread and water) ad libitum. This study was conducted in accordance with ethical procedures and policies approved by Animal Care and Use Committee of Faculty of Medicine, Al-Azhar University, Cairo, Egypt.Thirty two albino rats were randomly categorized into 4 groups, each group included 8 rats. Group I: control group in which the rats received distilled water. Group II: each animal was injected I.P with $0.5 \mathrm{mg}$ of BLM sulphate dissolved in $0.5 \mathrm{ml}$ of saline twice weekly for four weeks. Group III: in which the rats received BLM sulphate in the same previously described dose in group II \& ERD by a dose of $10 \mathrm{mg} / \mathrm{kg} / \mathrm{day}$ orally, two days before BLM administration. Group IV: received BLM sulphate in the same previously described dose in group II and captopril by a dose of $5 \mathrm{mg} / \mathrm{kg}$ orally for 4 weeks, two days before BLM administration.

At end of the experiment, the animals were sacrificed by decapitation under anesthesia then the lungs were dissected and small pieces of lung tissues were taken for the histological examination.

\section{Light microscopic examination:}

Specimens were fixed in neutral buffered formalin solution (10\%) and then dehydrated with ascending grades of ethyl alcohol $(70,80,90,95 \&$ $100 \%)$. Dehydration was then followed by clearing the samples in 2 changes of xylene ${ }^{(\mathbf{1 0})}$. Paraffin sections of $5 \mu \mathrm{m}$ thickness were prepared and stained with:

1- Haematoxylin and eosin $(\mathbf{H \& E})$, to study the histological structure of the lung tissue ${ }^{(\mathbf{1 0 )}}$.

2- Masson's trichrome stain for demonstration of the collagen fibers ${ }^{(\mathbf{1 0})}$.

Transmission electron microscopic examination:

The tissues obtained were fixed in fresh $3 \%$ glutaraldehyde for 4 hours. Then $1 \mathrm{~mm}$ specimens were cut and washed in $0.15 \mathrm{~mol} / \mathrm{l}$ phosphate buffer, $\mathrm{pH} 7.4$, for 2 hours (two changes), then post fixed in $1 \%$ osmium tetroxide for 1 hour. The specimens were dehydrated and embedded in epoxy resin. For electron microscopy, ultrathin sections (50-80 nm thick) were cut using the ultramicrotome and stained with uranyl acetate and lead citrate ${ }^{(\mathbf{1 1})}$. The sections were examined by the transmission electron microscope at the Unit of Electron Microscopy, Al-Azhar University, Cairo.

\section{RESULTS}

\section{Light microscopic examination}

Hematoxyltlin and eosin stained lung sections of the control rats showed the normal looking spongy appearance of the lung with thin alveolar septa and small bronchioles (Figures 1 and 2). The lining epithelium of alveoli was composed of flat type I alveolar cells and large cuboidal type II alveolar cells (Figure 2). With Masson's trichrome stain, sections from the control rats showed thin collagen fibers around the bronchioles and to a lesser degree in the alveolar septa (Figure 3).

Sections from lungs treated with BLM for four weeks revealed disturbance of lung structure. The results reported marked thickening in the alveolar septa with wide variation in the diameter of the alveoli, blood vessels with thick walls and marked cellular infiltration around the bronchioles and in the alveolar septa (Figure 4). We also observed blood vessel congestion and extravasation of blood into the interalveolar septa (Figure 5). The alveoli were lined with larger number of cubical alveolar cells with fewer number of type I flat cells and many vacuolated cells were noticed (Figure 6). Masson's trichrome stained sections showed large amount of collagen fibers around the bronchioles and few collagen fibers in the interalveolar septa (Figure 7).Sections from animals treated with both BLM and ERD showed some restoration of alveolar inflation of many alveoli with normal alveolar septal thickness but, some collapsed alveoli with thick septa could be noticed (Figure 8). The inflated alveoli were lined with flat type I alveolar cells and cuboidal type II alveolar cells(Figure 9) with some restoration of the percentage between the two types of cells. In Masson's trichrome stained sections, few collagen fibers were observed in the alveolar septa and around the bronchioles (Figure 10). On the other hand, sectionsof rats treated with BLM and captopril showed lesser structural improvement than in BLM and ERD treated sections. Focal areas of collapsed alveoli, overexpansion of others and few cellular infiltration around the bronchioles were observed (Figures 11and 12). In Masson's trichrome stained sections, many collagen fibers were observed around the bronchiole, but not in the interalveolar septa (Figure 13).

\section{Electron microscopic examination}

In lung of the control group, the alveoli were lined with type I alveolar cells with flat nuclei, type II alveolar cells with large rounded nuclei and alveolar macrophage (Figure 14).In BLM treated sections type I alveolar flat cells were less frequent. We observed many vacuoles in type II alveolar cells with mitochondria and lamellar bodies. Some lamellar bodies were empty and others had destructed lamellae (Figure 15). No apical microvilli were observed (Figures 15 and 16). Also, RBCs were found in the alveolar space (Figure 15). In other figures, type II alveolar cells were shrunken with irregular outlined nucleus and many cytoplasmic vacuoles (Figure 16). Adjacent cells, mostly type I alveolar cells, looked completely distorted and vacuolated (Figure 16). Collagen fibers with large amounts were found in the alveolar septa (Figures 16 and 17).Section treated 
with BLM and ERD showed type II alveolar cell with a nucleus that had regular outlines. Microvilli on the alveolar surface of type II cells were preserved. Lamellar bodies with thin fine concentric lamellae were observed, but some lamellar bodies were still empty (Figure 18).
In sections treated with BLM and captopril, we observed the presence of type II alveolar cell with mitochondria and a nucleus of regular outlines. Short and few microvilli were noticed. Some lamellar bodies had variable densities, others had fine intact lamellae and others were still empty (Figure 19).

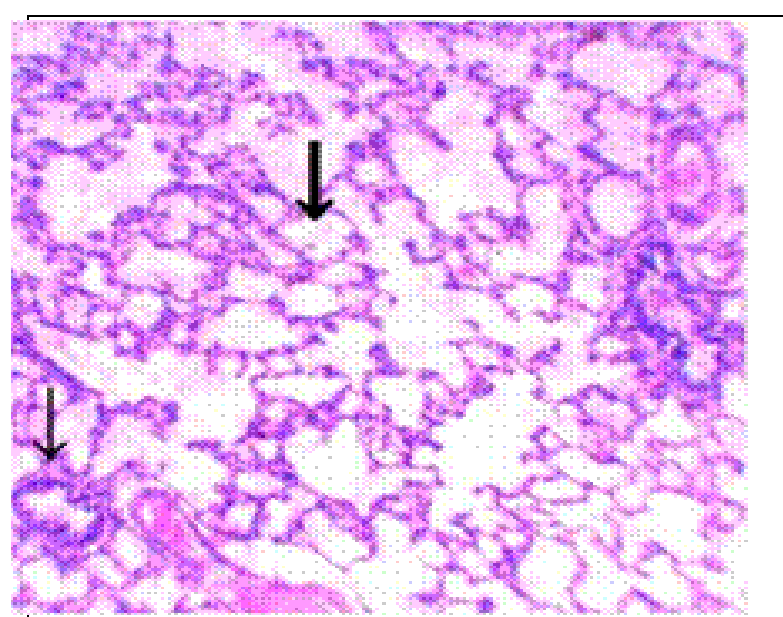

Figure1: a photomicrograph of lung section from a control rat showing the spongy structure of the lung that is formed of normally looking alveoli (thick arrow) with thin alveolar septa. Notice the presence of a small bronchiole (thin arrow).

(Hx \& E X 100)

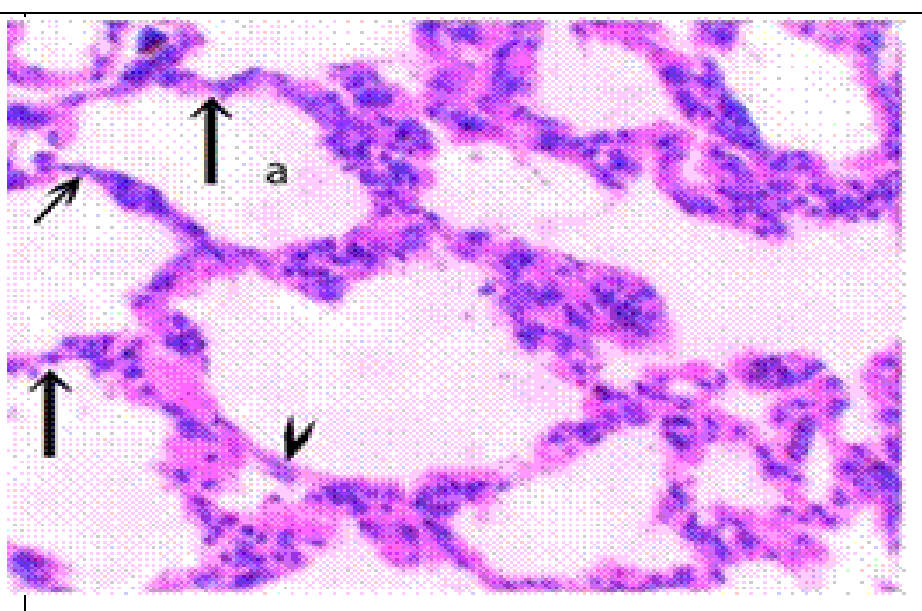

Figure2:a photomicrograph of a lung section from a control rat showing the spongy structure of the lung formed of normally looking alveoli (a) with thin alveolar septa (Thick arrow).The lining epithelium of alveoli is composed of flat type I (Arrow head) with flat nucleus and large cuboidal type II alveolar cells with rounded nucleus (Thin arrow).

(Hx \& E X 400)

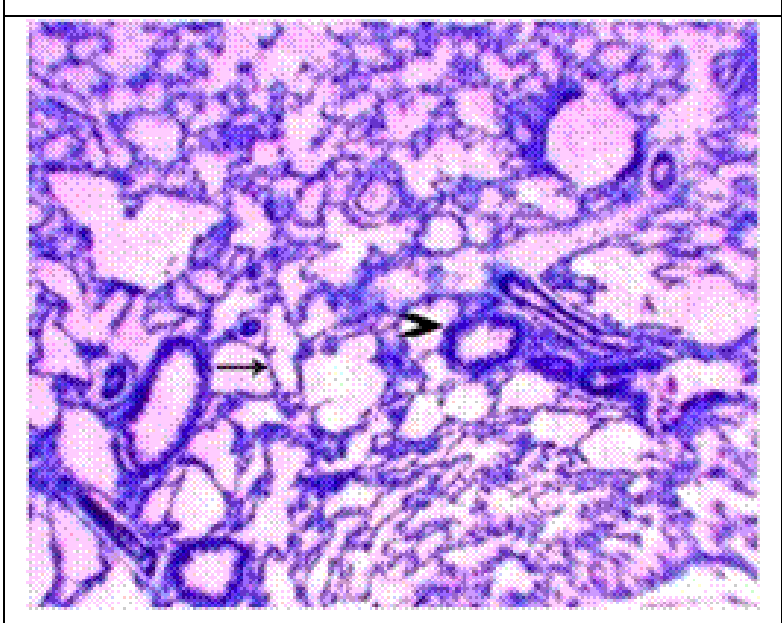

Figure3: a photomicrograph of a lung section from a control rat showing thin collagen fibers around the bronchioles (Arrow head) and in the interalveolar septa (arrow).

(Masson'strichrome stain X 100)

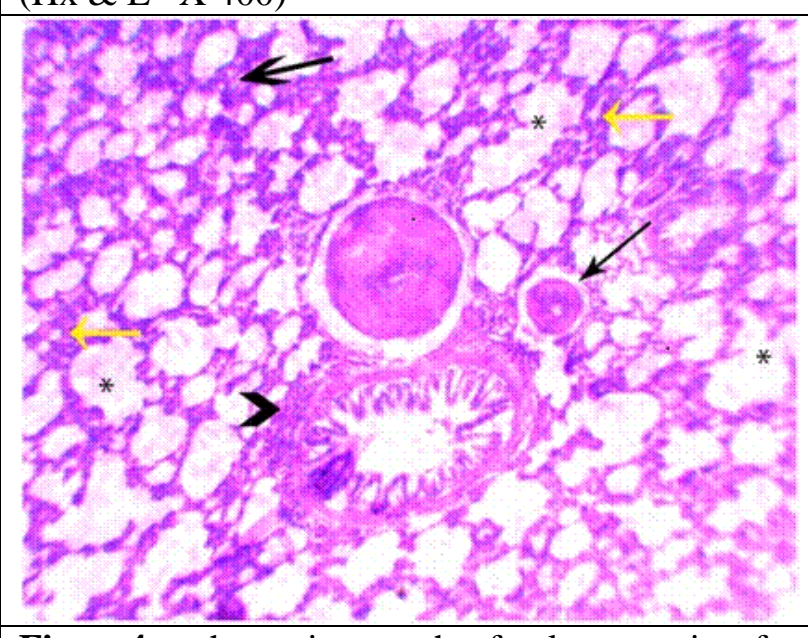

Figure4: aphotomicrograph of a lung section from rat treated with bleomycin showing marked thickening in the alveolar septa with collapsed alveoli (Yellow arrow). Other alveoli are widened (Star). There are thick blood vessels (Thin arrow). Notice the cellular infiltration around the bronchioles (Arrow head) and in the interalveolar septa (Thick arrow).

(Hx \& E X 


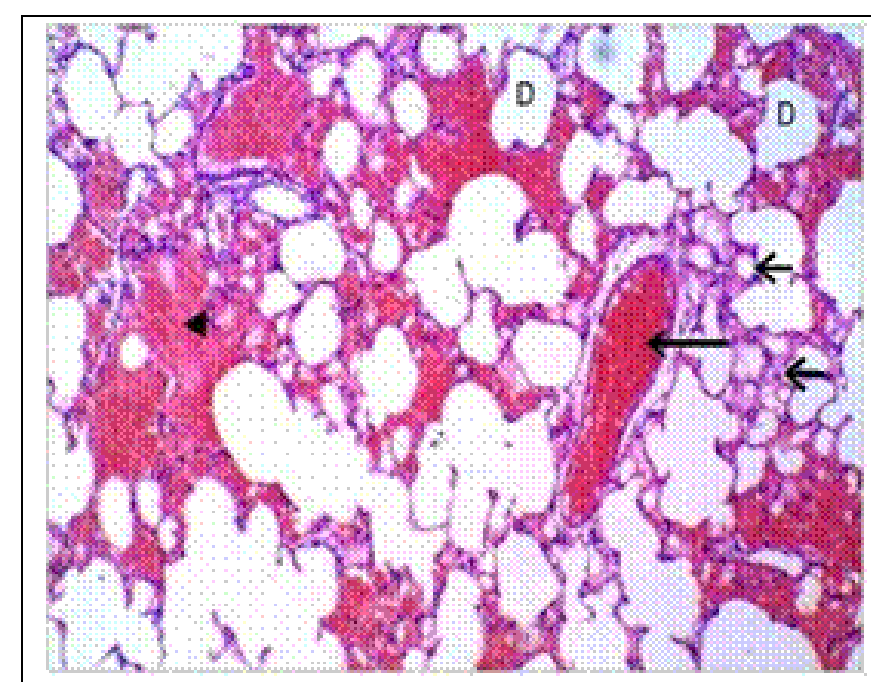

Figure 5: a photomicrograph of a lung section from a rat treated with bleomycin showing many dilated alveoli (D) and other collapsed alveoli (Thick short arrows). Notice the congested blood vessel (Long arrow) and the extravasted blood in the interalveolar septum (Arrow head). (Hx \& E X 100)

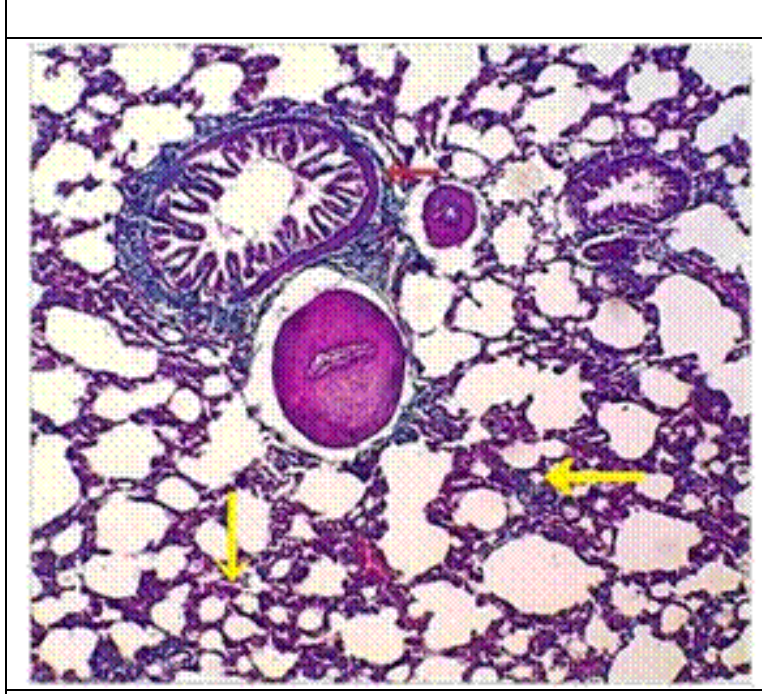

Figure 7: a photomicrograph of a rat lung section treated with bleomycin showing large amount of collagen deposition around the bronchiole (Orange arrow) and few collagen fibers in the interalveolar septum (Yellow arrows)(Masson'strichrome stain X 100).

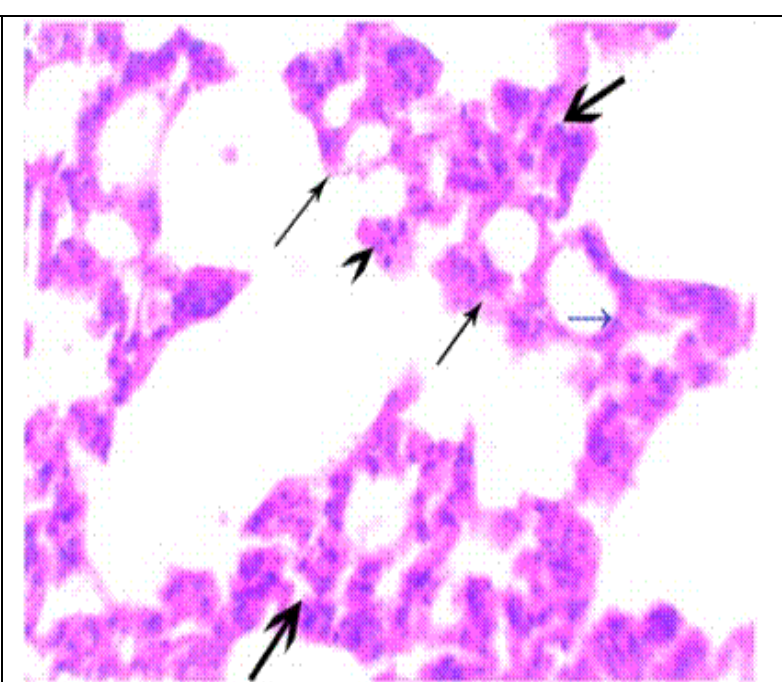

Figure 6: a photomicrograph of a rat lung section treated with bleomycin showing alveoli with variable sizes. The alveoli are lined with cuboidal type II alveolar cell (Arrow head) and flat type I alveolar cells (Blue arrow). There is a thickening in the interalveolar septa with collapsed alveoli (Thick arrow). Notice the presence of vacuolated cells (Thin arrow) in the alveolar wall.

(Hx \& E X 400)

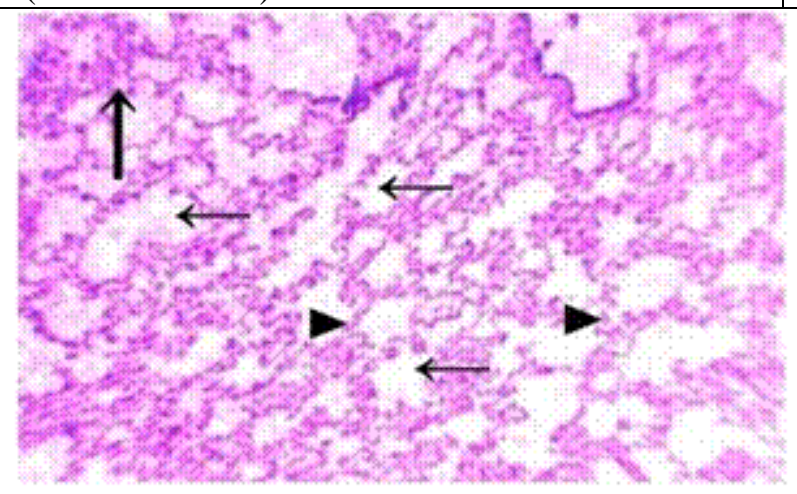

Figure 8: a photomicrograph of a rat lung section treated with bleomycin and ERD showing restoration of alveolar inflation (Thin arrows) of many alveoli with normal alveolar septal thickness (Arrow heads). Some collapsed alveoli with thick septa are also noticed (Thick arrow).

(Hx \& E X 100) 


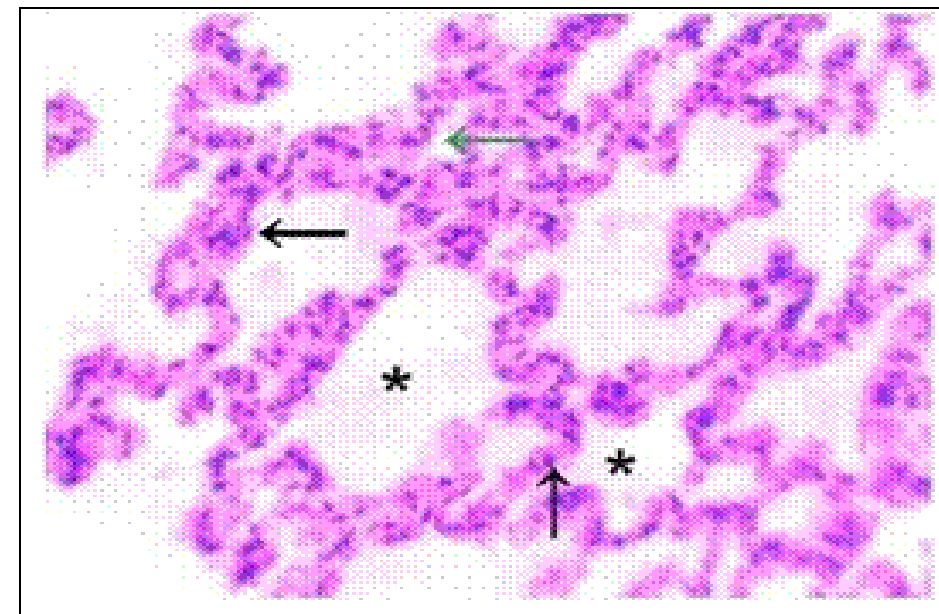

Figure 9: a photomicrograph of a rat lung section treated with bleomycin and ERD showing many inflated alveoli (Stars) lined with flat type I alveolar cells (Thick arrow) and cuboidal type II alveolar cells (Thin black arrow). Some collapsed alveoli with alveolar septum (Green arrow) can be also seen (Hx \& E X 400).

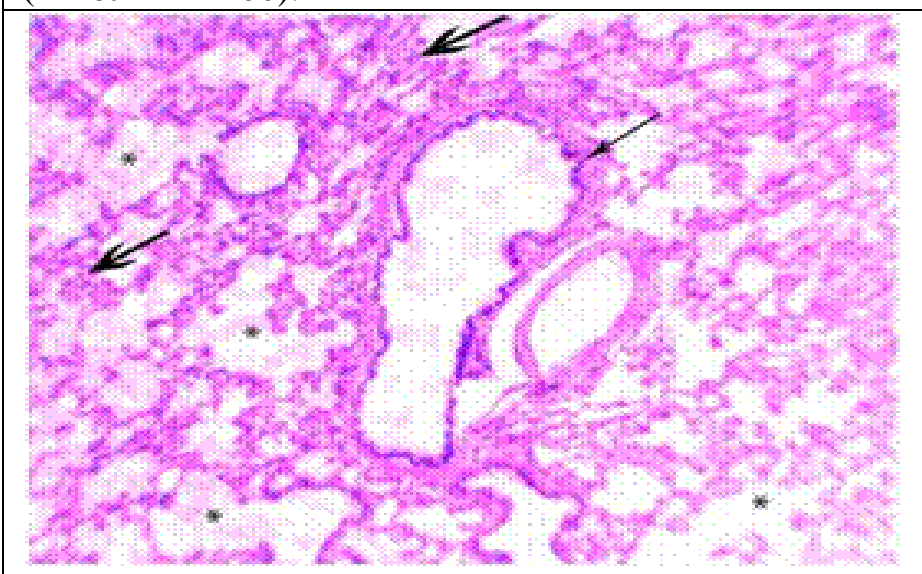

Figure 11: a photomicrograph of a rat lung section treated with bleomycin and captopril showing focal area of collapsed alveoli (Thick arrow), overexpansion of others (Star) and few cellular infiltrations around the bronchiole (Thin arrow). (Hx \& E X 100)

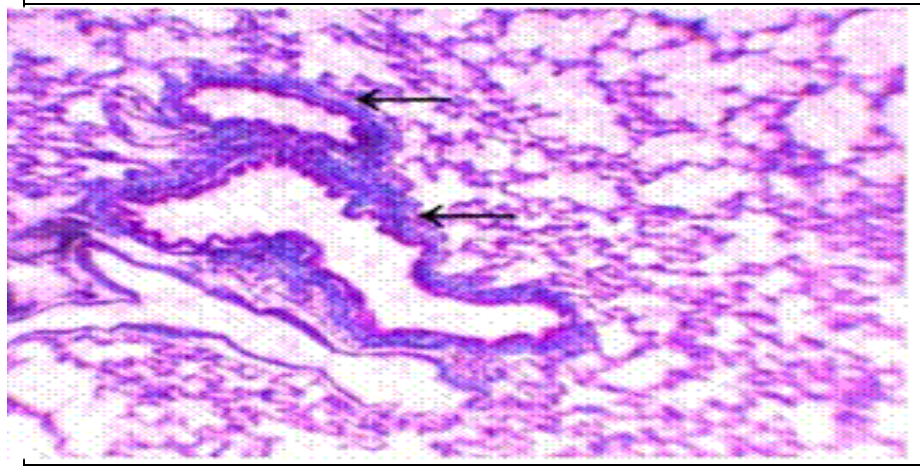

Figure13:a photomicrograph of a rat lung section treated with bleomycin and captopril showing many collagen fibers around the bronchiole (Arrows).

(Masson'strichrome stain X100)

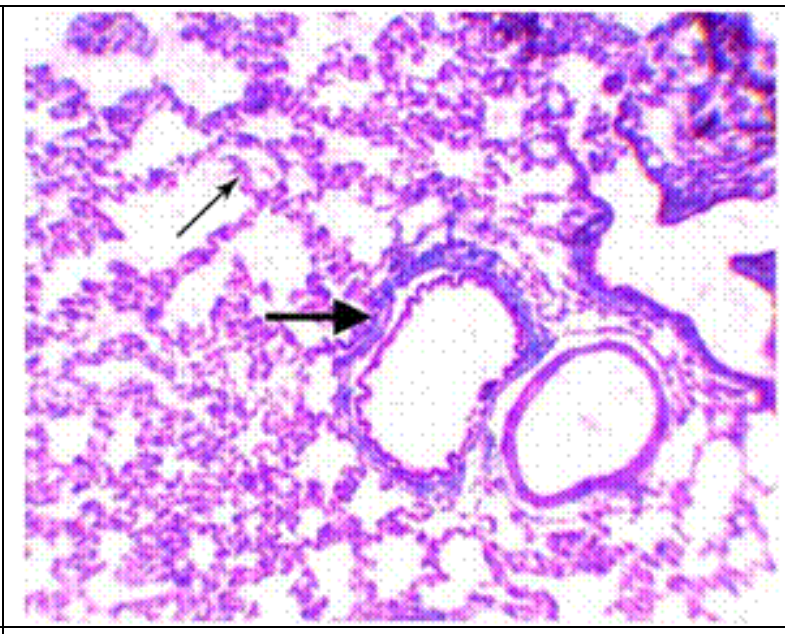

Figure 10: a photomicrograph of a rat lung section treated with bleomycin and ERD showing few collagen fibers in the alveolar septa (Thin arrow) and around the bronchiole (Thick arrow) (Masson'strichrome stain X 100)

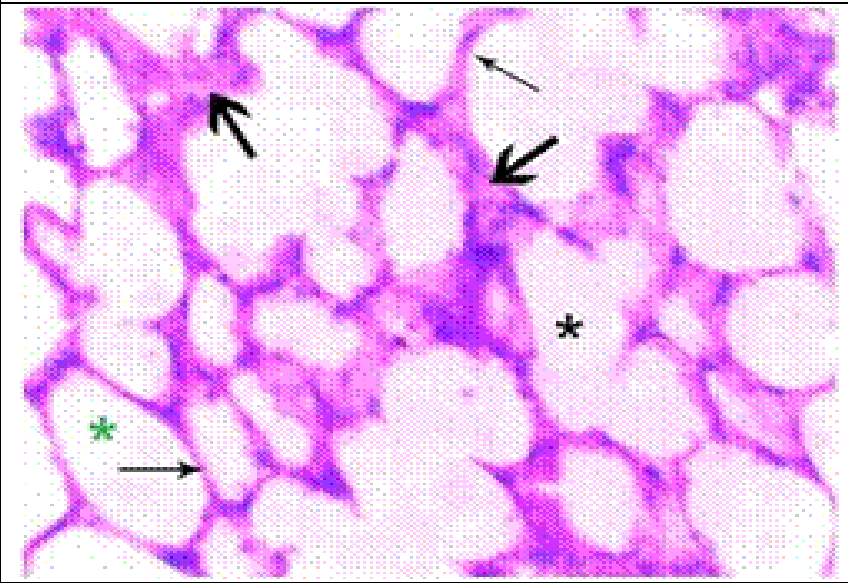

Figure12: a photomicrograph of a rat lung section treated with bleomycin and captopril showing normal appearance of alveoli (Green star) with thin alveolar septum (Thin arrow) and overexpanded alveoli (Black star). Notice the presence of collapsed alveoli with thick alveolar septa (thick arrows).(Hx \& E X 400) 


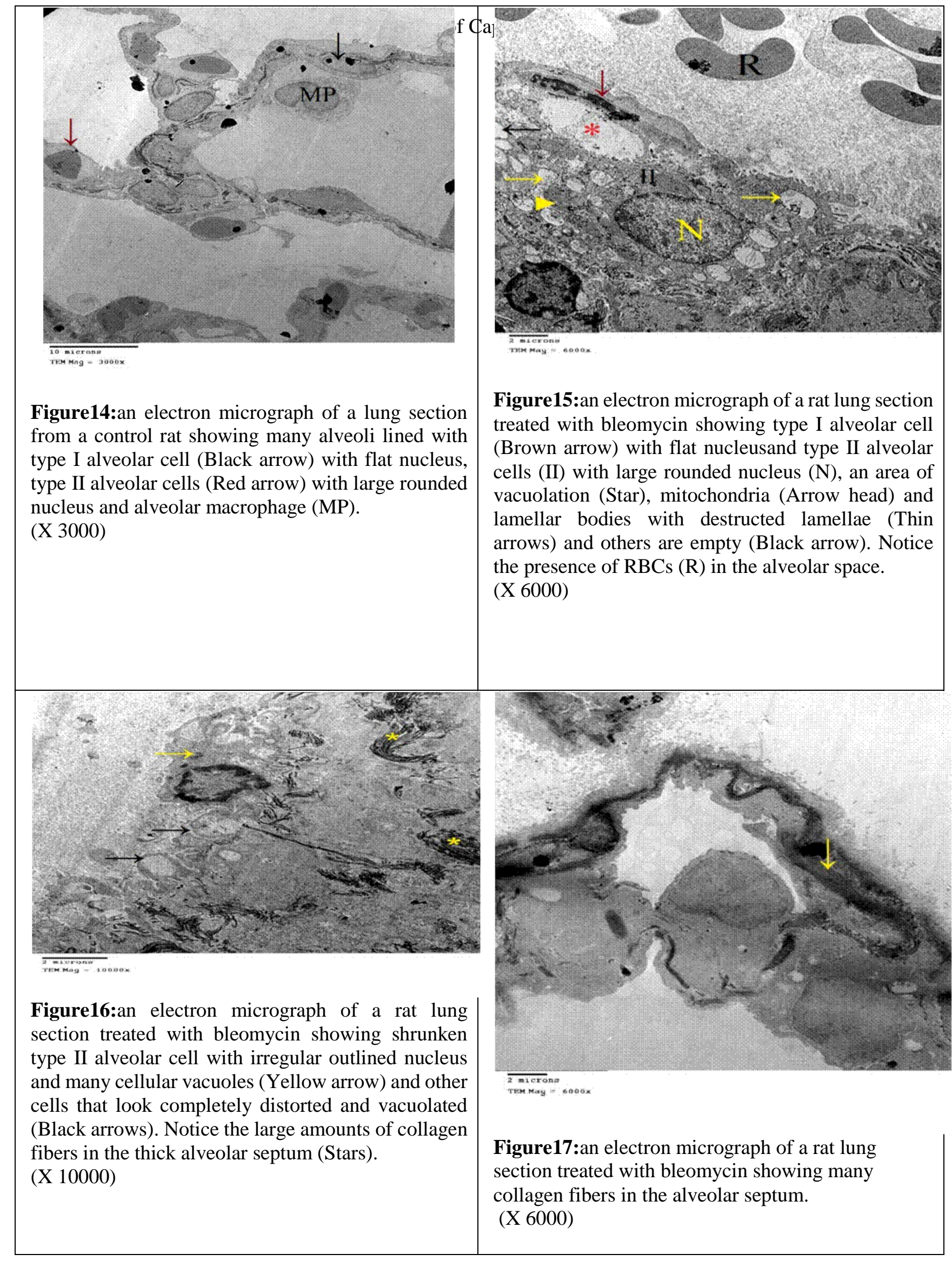




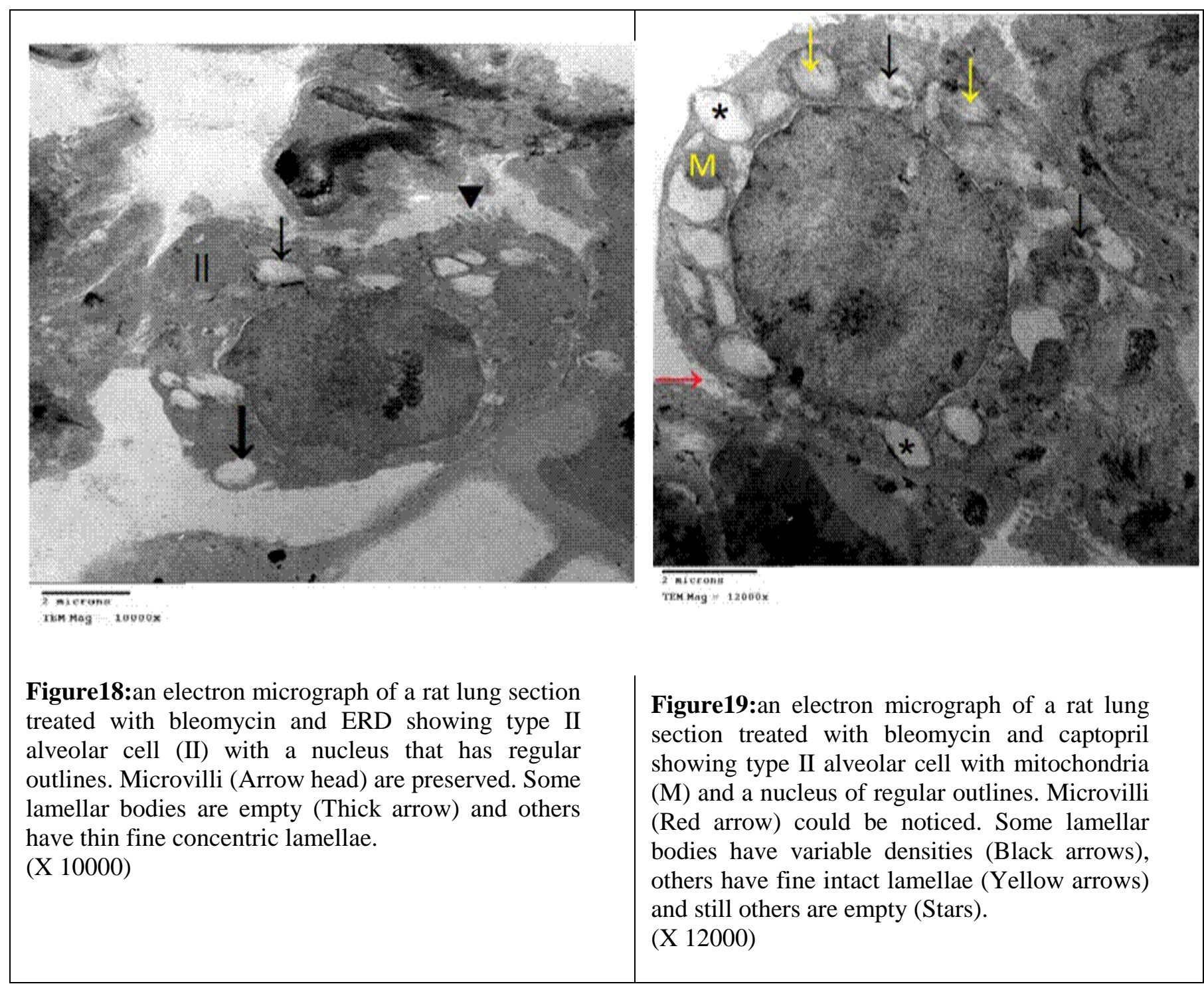

\section{DISCUSSION}

In the present study, animals treated with BLM showed disturbance of lung structure. The results revealed marked thickening in the alveolar septa with collapsed alveoli. Similar results were reported bymany authors ${ }^{(\mathbf{1 2}-14)}$.Some researchers attributed these changes to the inflammatory reaction, cellular infiltration in the alveolar septa and vascular congestion. Defective secretion of the pulmonary surfactant led to partial collapse of some alveoli ${ }^{(\mathbf{1 2})}$.

In the present study, other alveoli were overexpanded with destructed alveolar septa, a picture that resembles the histological appearance of emphysema ${ }^{(\mathbf{1 5})}$.This septal destruction could be caused by the proteolytic destruction of the lung parenchyma in the early stages of BLM-produced injury ${ }^{(\mathbf{1 6})}$. In the present work, thickening of the blood vascular walls, congestion and dilatation of blood vessels with extravasation of blood into the alveoli and alveolar septa were observed. Similar results were obtained bySalemet $\boldsymbol{a l} .{ }^{(\mathbf{1 3})}$ who reported that dilated congested blood vessels with extravasated red blood cells were noted in the BLM treated group. It was documented that BLM causes disruption of alveolar capillaries, increases alveolar capillary size and permeability and is responsible for formation of new vascular network ${ }^{(\mathbf{1 7 )}}$. In addition it was described that the main event in the development of pneumonitis and cellular infiltration is the endothelial damage of the lung vessels ${ }^{(18)}$.

Our results reported that administration of BLM increased collagen deposition in the lung interstitium with high degree of fibrosis. A similar observation was recorded in a previous work ${ }^{(\mathbf{1 9})}$. Administration of BLM may cause lung inflammation that can complicate to fibrosis due to increased concentration of reactive oxygen species and increased synthesis of mature collagen fibrils ${ }^{\mathbf{2 0})}$. It was also suggested that BLM may induce alveolar cells damage that may cause influx of inflammatory cells enhancing production and deposition of collagen and other matrix components with subsequent fibrosis ${ }^{(21)}$. 
As regards the alveolar lining cells, our study reported structural changes in both type I and II alveolar epithelial cells that revealed by light and electron microscopy. Marked decrease in type I alveolar cells, appearance of few vacuolated cells and many cuboidal cells which were detected by electron microscopy to be type II alveolar cells. So type II alveolar cells were the predominant cells lining the alveoli. Similar changes of the epithelial lining were previously reported by another study ${ }^{(22)}$ that attributed these findings to destruction of type I alveolar cell with subsequent replacement by the proliferating type II alveolar cells. They also reported that as type I cells represent the majority of the alveolar lining cells so they are more susceptible to injury with subsequent increase in pulmonary epithelial permeability in BLM -induced interstitial pneumonitis.Also, many type II alveolar cells showed some degenerative changes as empty lamellar bodies and loss of microvilli. These changes were suggested to be caused by the disturbed biochemical processes that involved the membranous components of the cytoplasm with subsequent imbalance in the distribution of fluids and electrolytes ${ }^{(23)}$. A studyshowed that the lung fibrosis and toxicity caused by BLM results from the chelation of iron ions with oxygen, which led to production of DNA-cleaving superoxide and also hydroxide free radicals ${ }^{(24)}$. It is the increased production of reactive oxygen species that lead to BLM pulmonary toxicity and may eventually leads to lung fibrosis and injury. Also the reactive oxygen species have been shown to activate profibrotic transforming growth factor- $\beta$ (TGF- $\beta$ ) which promotes the development of inflammation and induces the proliferation of the fibroblasts, leading to severe pulmonary fibrosis ${ }^{(25)}$. Administration of captopril or ERD resulted in improvement of the BLM related changes without reaching those of the control animals. The proliferative cuboidal cells replacing the disappeared type I alveolar cells were still observed. Restoration of normal size of some alveoli with normal alveolar septal thicknesswere detected but, some collapsed alveoli with thick septa were still noticed. Fewer collagen fibers could be observed in the alveolar septa and around the bronchioles. Microvilli on the alveolar surface of type II cells were partially preserved. Lamellar bodies with thin fine lamellae were observed but still some lamellar bodies were empty.ACEinhibitors are known to be able to block the renin-angiotensin system. They are used for the treatment of hypertension, congestive heart failure and other cardiovascular complications ${ }^{(26)}$.Reninangiotensin system is one of the pathogenic factors that play an essential role in the pathogenesis of pulmonary fibrosis (27). Angiotensin II up-regulates collagen gene expression in human lung fibroblasts and induces the proliferation of fibroblasts and collagen deposition ${ }^{(28)}$. Angiotensin II also stimulates apoptosis of alveolar epithelial cells, which is a key stage in the development of lung fibrosis ${ }^{(29)}$.Decreased collagen deposition in captopril treated groups was in agreement with a previous study designed by ${ }^{(\mathbf{8})}$ suggested that inhibition of ACE by captopril is the main pharmacological effective mechanism for inhibition of the fibrosis in experimental -induced lung injury by BLM. Angiotensin II seems to act as a fibroblast mitogen in the lung and as a mediator of fibroblast proliferation which appears to be linked to the production of TGF- $\beta^{(\mathbf{3 0})}$. Supporting this point of view, a study showed that TGF- $\beta$, a multifunctional cytokine, is the main cytokine involved in the process of fibrosis via the conversion of fibroblasts to myofibroblasts and collagen synthesis ${ }^{(31)}$.Captopril has the ability to eradicate the oxygen free radicals, stimulate the recovery of lung vascular endothelial dysfunction and decrease the vascular permeability that improve the tissue edema and inflammatory exudation leading to decrease of alveolar septal thickness. It has a significant antiinflammatory and antifibrolytic effects ${ }^{(32)}$. Forushaniet al. ${ }^{(\mathbf{1 9})}$ demonstrated the protective effect exerted by valsartan as an antagonist of angiotensin receptor in BLM-induced pulmonary fibrosis by decreasing the collagen content in lung tissue. On the other hand, the improvement recorded by ERD in our results was in agreement with the results reported byGuzelet al ${ }^{(14)}$ who concluded that in the BLM+ERD group, interalveolar septal thickening of the lung tissue was decreased compared to BLM group. Interstitial thickening was not diffuse, and remained only in some local areas. Peribronchiolar lymphocytic infiltration was detected in connective tissues. Erden et al. ${ }^{\left({ }^{33}\right)}$ studied the effectiveness of ERD in a pulmonary fibrosis model, using BLM in rats, and demonstrated that ERD prevented neutrophil accumulationby inhibiting acute lung injury and fibrosis, lipid peroxidation and chemokine production. Boyac et al. ${ }^{(34)}$ claimed that ERD served as a free radical scavenger to inhibit peroxidation of membrane lipids, and may maintain cell membrane integrity and function, thus preventing protein leakage and accumulation ${ }^{(33)}$.Demiralay et al. $^{\left({ }^{(35)}\right.}$ demonstrated that ERD exhibited protective effects on lipopolysaccharide-induced lung injury by decreasing the neutrophil influx into lungs and thus reduced the production of oxygen free radicals that cause lung injury and alveolar cells destruction.

\section{REFERENCES}

1. Gross TJ and Hunninghake GW (2001): Idiopathic pulmonary fibrosis. N. Engl. J. Med., 345:517-525.

2. Rahman I and MacNee W (2000): Oxidative stress and regulation of glutathione in lung inflammation. Eur. Respir.J., 16: $534-554$.

3. Hardman JG, Limbird LE and Gilman AG (2001): The pharmacological Basis of therapeutics. $100^{\text {th }}$ ed. McGrawHill.New York.

4. Filderman AE, Genovese LA and Lazo JS (1988): Alteration in pulmonary protective enzymes following 
systemic bleomycin treatment in mice. Biochem.Pharmacol., 37: 1111- 1116.

5. Oury TD, Thakker K, Menache $M$ and Chang LV (2001): Attenuation of bleomycin-induced pulmonary fibrosis by a catalytic antioxidant metalloporphyrin. Am. J. Respir. Cell Mol. Biol., 25: 164-169.

6. Noppen M, Degreve J, Mignolet $M$ and Vincken W (1997): A prospective, randomized study comparing the efficacy of talc slurry and bleomycin in the treatment of malignant pleural effusions. Acta Clin. Belg., 52(5):258-262.

7. Brown NJ and Vaughan DE (1998): Angiotensinconverting enzyme inhibitors. Circulation, 97: 1411-1420.

8. Ghazi-Khansari M, Nasiri G and Honarjoo M (2005): Decreasing the oxidant stress from parquet in isolated perfused rat lung using captopril and niacin. Arch Toxicol., 79: 341345.

9. Dechant KL and Noble S (1996): Erdosteine. Drugs, 52 (6): 875-881.

10. Bancroft JD and Gamble M (2008): Theory and Practice of Histological Techniques. $6^{\text {th }}$ ed. Churchill Livingstone.London.

11. Hayat MA (2000): Principles and Techniques of Electron Microscopy: Biological Applications. $4^{\text {th }}$ ed. Edinburgh: UK, Cambridge University Press.pp: 37-59.

12. Usuki F Y (1995): Evolution of three patterns of intraalveolar fibrosis produced by bleomycin in rats. Pathol. Int., 45(8):552-564.

13. Salem MY, El-Azab NE and Faruk EM (2014): Modulatory effects of green tea and aloe vera extracts on experimentally-induced lung fibrosis in rats: histological and immunohistochemical study. J. Histol. Histopathol., 1(6): 1-7. 14. Guzel A, Kayhan S, Tutuncu S, Guzel A, Duran L, Alacam H, Gunaydin M, Caglar TA, Yilmaz MZ, Selcuk MY and Murat N (2015): Attenuation of bleomycin induced lung fibrosis by erdosteine and inhibition of the inducible nitric oxide synthase. Bratisl. Lek. Listy, 116 (3):196-202

15. Borzone G, Moreno R, Urrea R, Meneses M, Oyarzun $M$ and Lisboa $C$ (2001): Bleomycin-induced chronic lung damage doesnot resemble human idiopathic pulmonary fibrosis. Am. J. Respir., 163(7):1648-1653.

16. Sullivan JB and Krieger GR (2001): Clinical Environmental Health and Toxic Exposure. Lippincott Williams \& Wilkins.Philadelphia. pp: 867-879.

17. Peao MN, Aguas AP, deSa CM and Grande NR (1994): Neoformation of blood vessels in association with rat lung fibrosis induced by bleomycin. Anat. Rec., 238(1):57-67.

18. Uzel I, Ozguroglu M, Uzel B, Kaynak K, Demirhan O, Akman C and Oz F and Yaman M (2005): Delayed onset bleomycin-induced pneumonitis. Urology, 66(1):195-200.

19. Forushani HM, Hemmati AA, Khodadadi A, Assarehzadegan MA and Rashno M (2017): Protective effect of valsartan on beleomycine-induced fibrosis. Jundishapur J. Nat. Pharm. Prod., 12(1):33973-33980 .

20. Atzori L, Chua F, Dunsmore SE, Willis D, Barbarisi M, McAnulty RJ and Laurent GJ (2004): Attenuation of bleomycin induced pulmonary fibrosis in mice using the heme oxygenase inhibitor Zn-deuteroporphyrin IX-2,4-bisethylene glycol. Thorax, 59(3):217-223

21. Aoshiba K, Tsuji T and Nagai A (2003): Bleomycin induces cellular senescence in alveolar epithelial cells. Eur. Respir. J., 22(3):436-443.
22. Mahdi MT and Ibrahim MK (2015): Effect of losartan drug on pulmonary fibrosis induced by bleomycin in experimental rats. International J. Pharm. Tech. Research, 7(2): 314-319.

23. Nakama K, Miyazaki $Y$ and Nasu M (1998): Immunophenotyping of lymphocytes in the lung interstitium and expression of osteopontin and interleukin-2 mRNAs in two different murine models of pulmonary fibrosis. Exp. Lung Res., 24(1):57-70.

24. Lawrenz J, Herndon B, Kamal A, Mehrer A, Dim DC, Baidoo C, Gasper D, Nitz J, Molteni A and Baybutt RC (2012): Dietary flaxseed oil protects against bleomycininduced pulmonary fibrosis in rats. Pulm Med., 45703.

25. Shi K, Jiang J, Ma T, Xie J, Duan L, Chen R, Song P, Yu Z, Liu C, Zhu Q and Zheng J (2014): Pathogenesis pathways of idiopathic pulmonary fibrosis in bleomycininduced lung injury model in mice. Respir. Physiol. Neurobiol., 190:113-117.

26. Atlas SA (2007): The renin-angiotensin aldosterone system: pathophysiological role and pharmacologic inhibition. J. Managed Care Pharmacy, 13(8): 9-20.

27.Shenoy V, Ferreira AJ, Qi Y, Fraga-Silva RA, DíezFreire C, Dooies A, Jun JY, Sriramula S, Mariappan N, Pourang D, Venugopal CS, Francis J,ReudelhuberT, Santos RA, Patel JM, Raizada MK and Katovich MJ(2010): The angiotensin-converting enzyme 2/angiogenesis-(1-7)/Mas axis confers cardiopulmonary protection against lung fibrosis and pulmonary hypertension. Am. J.Respir. Critical Care Med., 182(8): 1065-1072.

28.Otsuka M, Takahashi H, Shiratori M, Chiba H and Abe S (2004):Reduction of bleomycin induced lung fibrosis by candesartan cilexetil, an angiotensin II type 1 receptor antagonist. Thorax, 59(1): 31-38.

29.Wang R, Zagariya A, Ibarra-Sunga O, Gidea C, Ang E, Deshmukh S, Chaudhary G Baraboutis J, Filippatos G and Uhal BD (1999): Angiotensin II induces apoptosis in human and rat alveolar epithelial cells. Am. J. Physiol. Lung Cell Mol. Physiol., 276(5): 885-889.

30. Marshall RP, Gohlke P, Chambers RC, Howell DC, Bottoms SE, Unger T, McAnulty RJ and Laurent GJ (2010): Angiotensin II and the fibroproliferative response to acute lung injury. Am. J. Physiol. Lung Cell Mol .Physiol., 286: $156-164$.

31. Nadrous HF, Pellikka PA, Krowka MJ, Swanson KL, Chaowalit N, Decker PA and Ryu JH (2005): The impact of pulmonary hypertension on survival in patients with idiopathic pulmonary fibrosis. Chest, 128: 616-617.

32. Yu M and Tian ZF (2014): Biomarkers in acute lung injury. Chin. J. Contemporary Pediatrics, 16(1): 95-98.

33. Erden ES, Kirkil G and Deveci F (2008):Effects of erdosteine on inflammation and fibrosis in rats with pulmonary fibrosis induced by bleomycin. Tuberk Toraks, 56 (2): 127138.

34. Boyac HS, Maral H, Turan G, Basyi ̌git I, Dillioglugil MO, Yıldız F, Tugay $M$ and Ercin $\mathbf{C}(2006)$ : Effects of erdosteine on bleomycin-induced lung fibrosis in rats. Mol Cell Biochem., 281: 129-137.

35. Demiralay R, Gürsan N, Özbilim G, Erdoan G and Demirci E (2006): Comparison of the effects of erdosteine and $\mathrm{N}$-acetylcysteine on apoptosis regulation in endotoxin-induced acute lung injury. J. Appl. Toxicol., 26: 301-308. 